\title{
Molecular $\mathrm{Cu}(\mathrm{I})-\mathrm{Cu}(\mathrm{II})$ Photosensitizer-Catalyst Photoelectrode for Water Oxidation
}

Zujhar Singh, Pedro R. Donnarumma, and Marek B. Majewski*

Department of Chemistry and Biochemistry and Centre for NanoScience Research

Concordia University

7141 Sherbrooke Street West, Montreal, Quebec, Canada, H4B 1R6

E-mail: marek.majewski@concordia.ca

KEYWORDS: Solar fuels - Photocatalysis - Photoelectrochemistry - Donor-ChromophoreAcceptor $•$ Water Oxidation 
For the Table of Contents Only

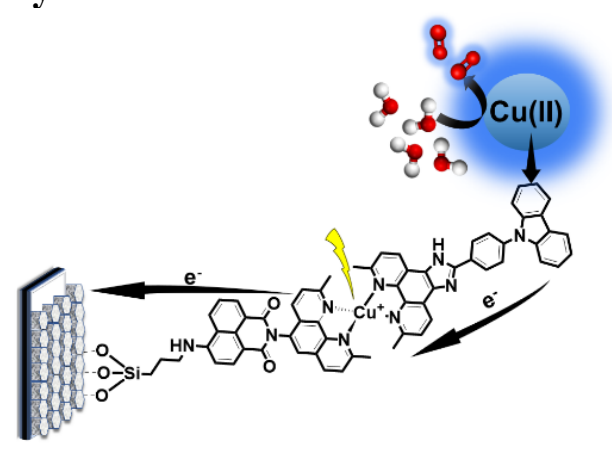




\section{ABSTRACT}

Photochemical splitting of $\mathrm{H}_{2} \mathrm{O}$ to $\mathrm{H}_{2}$ and $\mathrm{O}_{2}$ is one approach to generate "solar fuels." $\mathrm{Cu}(\mathrm{II})-$ based electrocatalysts for water oxidation in aqueous solution have been studied previously, but photodriving these systems still remains a challenge. Light harvesting units can be employed for this purpose, that upon photoexcitation generate a high energy excited state and give rise to a charge separated state (CSS). In this work, a bis-diimine $\mathrm{Cu}(\mathrm{I})$-based donor-chromophore-acceptor (D-C-A) system is synthesized, characterized, and applied as the light harvesting component of a photoanode. Here, this molecular assembly was integrated onto a zinc oxide $(\mathrm{ZnO})$ nanowire surface on a fluorine-doped tin oxide (FTO) glass slide. Upon photoexcitation, chronoamperometric studies reveal that the integrated triad can inject electrons directly into the conduction band of zinc oxide generating oxidizing equivalents that are then transferred to a $\mathrm{Cu}(\mathrm{II})$ water oxidation catalyst in aqueous solution yielding $\mathrm{O}_{2}$ from $\mathrm{H}_{2} \mathrm{O}$ with a Faradaic efficiency of $76 \%$. 
The storage of solar energy in chemical bonds (i.e. artificial photosynthesis) holds promise as an alternative energy strategy. One example of this strategy is the photocatalytic splitting of $\mathrm{H}_{2} \mathrm{O}$ molecules to give $\mathrm{O}_{2}$ and successive proton reduction to give $\mathrm{H}_{2} .{ }^{1}$ The key challenge for efficient water splitting is to accumulate four oxidative equivalents at a single catalytic site to drive the oxidation of $\mathrm{H}_{2} \mathrm{O}{ }^{2}$ One attractive approach is to use light harvesting moieties (i.e. photosensitizers/chromophores) coupled to wide bandgap semiconductor nanostructures and a molecular water oxidation catalyst to photochemically generate the redox equivalents needed to split $\mathrm{H}_{2} \mathrm{O}$ (this ensemble gives the photoanode of a dye-sensitized photoelectrochemical cell, DSPEC) ${ }^{3-5}$ In this capacity, molecular donor-chromophore-acceptor (D-C-A) systems, where the chromophore (C) is a transition metal complex bearing an electron donor moiety (D) and an electron acceptor (A) moiety are well-established molecular architectures often employed to reach a long-lived charge separated state that can subsequently be used to drive follow-on reactions. ${ }^{6-8}$ Of significance is how this motif mimics the charge separation and transfer processes occurring in natural photosynthesis, but is rarely employed in DS-PEC architectures likely due to the complexity of synthetically incorporating surface anchoring groups into the molecular structure of the final adduct. ${ }^{9}$

Herein, we report a new $\mathrm{Cu}(\mathrm{I})$-based donor-chromophore-acceptor triad D1-C-A1 (Figure 1) in which a heteroleptic 2,9-dimethyl-1,10-phenanthroline $\mathrm{Cu}(\mathrm{I})$ chromophore adduct (C) bearing a 1,8-napthalene monoimide (NMI) electron accepting moiety ${ }^{10}$ (A1) and a carbazole electron donating moiety ${ }^{11}$ (D1) serves to generate a charge separated state. The acceptor ligand A1 is designed and synthesized in such a way as to perform the dual roles of (a) anchoring to a semiconductor surface as well as (b) electron accepting to afford directional charge transport. Grafting this molecular system onto zinc oxide nanowires ( $\mathrm{ZnO}$ NWs) on a transparent conducting 
oxide (fluorine doped tin oxide, FTO) followed by photoexcitation gives rise to electron injection directly into the conduction band of $\mathrm{ZnO}$. The resulting oxidizing equivalents are then transferred to a $\mathrm{Cu}(\mathrm{II})$ water oxidation catalyst $[(\mathrm{bpy}) \mathrm{Cu}(\mu-\mathrm{OH})]_{2}\left[\mathrm{SO}_{4}\right]$ (bpy $=2,2^{\prime}$-bipyridine, Figure 1$)$ in aqueous solution yielding a photoanode ensemble capable of driving water oxidation catalysis.

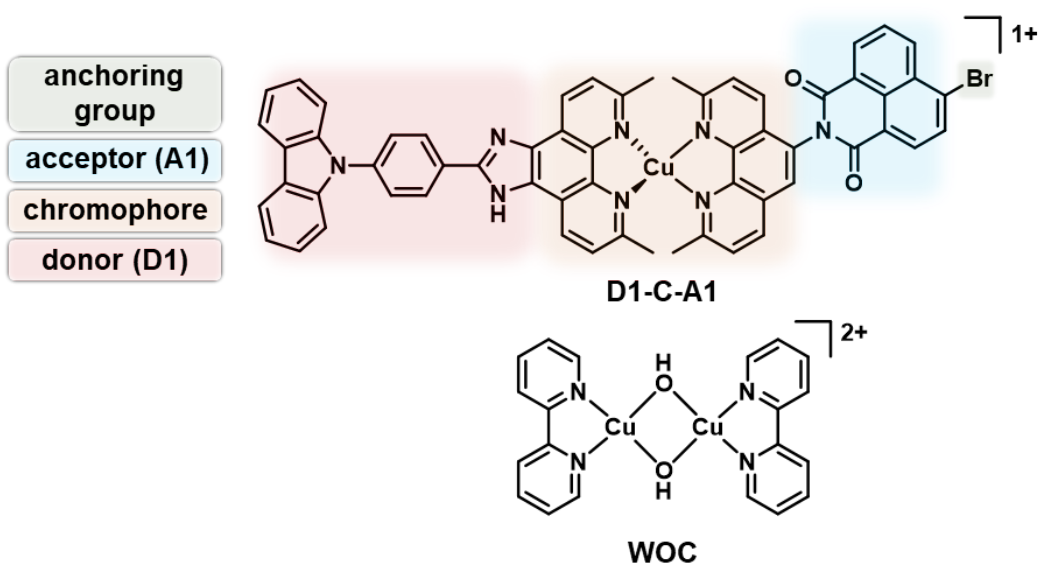

Figure 1. Structures of the triad D1-C-A1 and the water oxidation catalyst (WOC) employed in this work.

The donor (D1) and acceptor (A1) ligands were synthesized using modifications of previously reported literature procedures (Scheme S1). ${ }^{12,13}$ The $\mathrm{Cu}(\mathrm{I})$ based donor-chromophore-acceptor (D1-C-A1) system was synthesized in good yield using a one pot, two-step reaction via the HETPhen methodology (Scheme S2). ${ }^{14,15}$ The same synthetic approach was used to make model complexes bearing either just the electron acceptor (C-A1) or donor ligand (D1-C). All the complexes were isolated as $\mathrm{BF}_{4}$ salts and the identities were confirmed using ${ }^{1} \mathrm{H}$ and ${ }^{13} \mathrm{C}$ NMR spectroscopy, high resolution ESI mass spectrometry, UV-Vis spectroscopy, and electrochemistry. The $\mathrm{Cu}(\mathrm{II})$ based water oxidation catalyst $\left[(\mathrm{bpy}) \mathrm{Cu}(\mu-\mathrm{OH})_{2}\left[\mathrm{SO}_{4}\right]\right.$ (WOC) was synthesized using previously reported procedures. ${ }^{16,17}$ 
The ground state optical properties of D1, A1, D1-C-A1, C-A1, and D1-C, were investigated in dichloromethane. As expected, UV-Vis spectra of all the complexes exhibit broad ${ }^{1}$ MLCT absorption bands centered at ca. $460 \mathrm{~nm}$ (Figure 2A). The UV-Vis spectrum of D1-C-A1 is effectively a sum of the spectra for the corresponding dyads D1-C and C-A1, confirming a weak ground state interaction between the D1 and A1 moieties and the metal center. The electrochemical behavior of all the complexes was investigated using cyclic voltammetry (Figure 2B) and differential pulse voltammetry (Figure S1) in degassed dichloromethane under argon atmosphere. In all of the complexes, a well-defined reversible oxidation wave was observed at ca. $E_{o x}=+0.51$ $\mathrm{V}$ (all potentials reported versus ferrocene/ferrocenium redox couple) and was assigned to the $\mathrm{Cu}(\mathrm{I}) / \mathrm{Cu}(\mathrm{II})$ redox couple (Figure 2B). The presence of the carbazole moiety in dyad D1-C and triad D1-C-A1 is confirmed through the appearance of one additional wave at $\mathrm{E}_{\mathrm{ox}}=+0.95 \mathrm{~V}$ and $+0.90 \mathrm{~V}$, respectively. ${ }^{11}$ The first reduction of the NMI moiety ${ }^{13}$ in the D1-C-A1 triad was observed at $\mathrm{E}_{\text {red }}=-1.56 \mathrm{~V}$ which is more cathodic than the first reduction observed in the $\mathbf{C}-\mathbf{A} \mathbf{1}$ dyad of $\mathrm{E}_{\text {red }}=-1.48 \mathrm{~V}$, which is further shifted to lower potentials than the first reduction of the ligand $\mathbf{A 1}\left(\mathrm{E}_{\text {red }}=-1.37 \mathrm{~V}\right)$. 

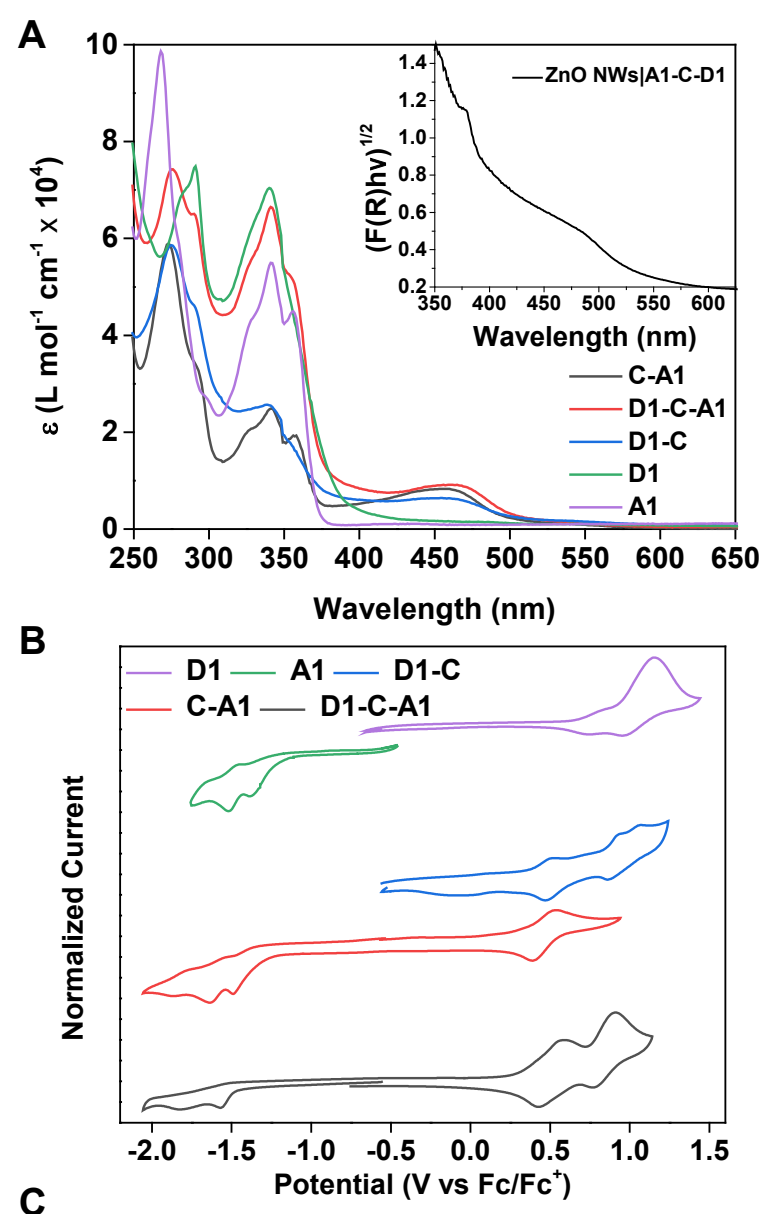

C

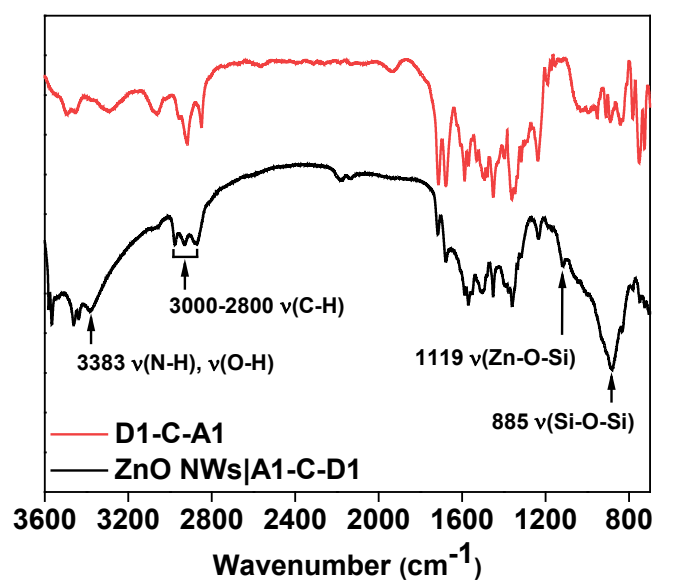

Figure 2. A) UV-Vis spectra of D1, A1, A1-C, C-D1 and D1-C-A1 in $\mathrm{CH}_{2} \mathrm{Cl}_{2}$ at room temperature and. B) Cyclic voltammograms of ligand D1 (purple trace), ligand A1 (green), D1-C (blue), C-A1 (red), D1-C-A1 (black). Voltammograms recorded in $0.1 \mathrm{M} n-\left[\mathrm{Bu}_{4} \mathrm{~N}\right] \mathrm{PF}_{6}$ in $\mathrm{CH}_{2} \mathrm{Cl}_{2}, 100 \mathrm{mV} / \mathrm{s}, 3$ mm platinum button working electrode (WE), a Pt wire as counter electrode (CE), Ag wire 
reference electrode (RE), and ferrocene ( $\mathrm{Fc}$ ) as an internal standard. C) Overlaid $\mathrm{UV}$-Vis spectrum of D1-C-A1 (red) with diffuse reflectance spectrum (DRS) of sensitized ZnO NWs|A1-C-D1 nanorods (black) D) Overlaid diffuse reflectance infrared Fourier transform (DRIFTS) spectra of D1-C-A1 powder (red) with D1-C-A1 sensitized ZnO nanoparticles (black).

Computational density functional theory (DFT) calculations performed on D1-C, C-A1, and D1C-A1 gave insight into the localization of the frontier molecular orbitals (Figure 3, Tables S1-S3). In D1-C-A1 the HOMO is delocalized over the carbazole and phenyl bridge of D1 and the LUMO is centered on the NMI of A1. This separation between the D1 and $\mathbf{A} 1$ centered orbitals partially confirms the success of our design strategy for directional electron transport in D1-C-A1 because charge shift is expected to lead to a reducing equivalent being localized on A1, affording a pathway for injection into a semiconductor. ${ }^{18}$
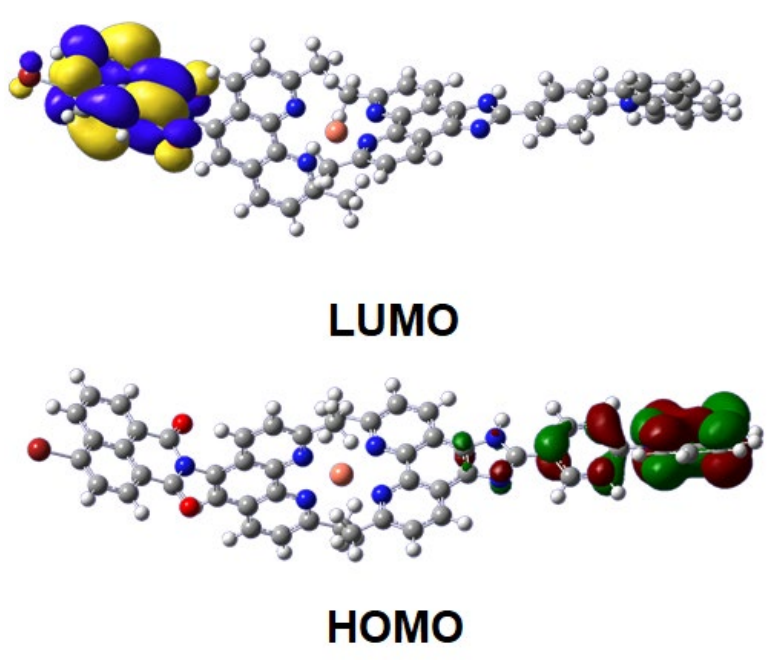

Figure 3. Graphical representation of HOMO and LUMO of D1-C-A1. 
The excited state redox potentials for D1-C-A1 were estimated by taking the difference of the intersection of the absorption and emission spectra of $\left[\mathrm{Cu}(\mathrm{dmp})_{2}\right]\left[\mathrm{BF}_{4}\right](\mathrm{dmp}=2,9$-dimethyl-1,10phenanthroline, $\mathrm{E}_{00}=2.04 \mathrm{eV}$ in $\left.\mathrm{CH}_{2} \mathrm{Cl}_{2}\right)^{19}$ since D1-C-A1 is non-emissive, and the ground state redox potentials. ${ }^{6}$ This gives excited state potentials $\mathrm{E}^{*}{ }_{\mathrm{ox}}$ and $\mathrm{E}^{*}$ red of -1.14 and $0.88 \mathrm{~V}$, respectively, indicating that the excited state of D1-C-A1 is both a good oxidant and reductant, with an excited state oxidation potential approaching that needed to drive water oxidation $(0.81 \mathrm{~V}$ vs NHE at $\mathrm{pH} 7) .{ }^{20}$ The involvement of the carbazole moiety in any charge transfer process is not immediately apparent, as the oxidation potential of $\mathbf{D 1}$ falls well above that of the $\mathrm{Cu}(\mathrm{II} / \mathrm{I})$ redox couple. Indeed, by estimating the thermodynamics of the system from the ground state electrochemistry, a charge separated state with a hole localized on the carbazole and an electron localized on the NMI moiety with $\mathrm{Cu}$ in the +1 oxidation state (i.e. the excited state having been

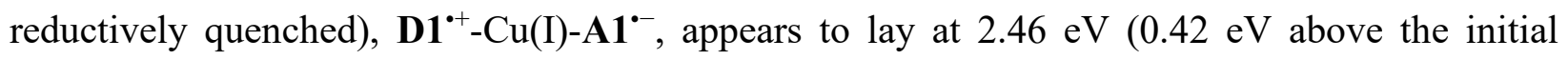
excited state). Conversely, the state where charge shift has occurred between the excited state of

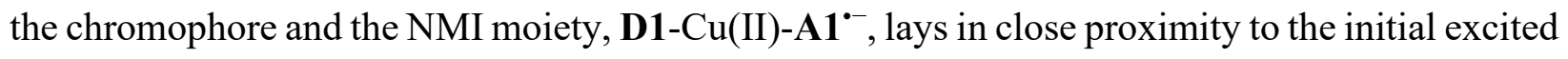
state at $2.07 \mathrm{eV}$ indicating that this state may, at least in solution, be energetically accessible. ${ }^{21} \mathrm{We}$ postulate that planarization of the components (vide infra) of the triad once it is immobilized on an electrode surface may influence this thermodynamic relationship making the fully charge separated state more accessible. ${ }^{22-24}$

To construct a photoelectrode to use in a DS-PEC, the sensitization of oriented, solvothermally grown ZnO NWs on FTO (Figure S2) with D1-C-A1 was carried out through modification of previously reported surface grafting procedures (Scheme S3). ${ }^{25-28}$ The resulting films were characterized using diffuse reflectance UV-Vis spectroscopy (DRS) the outcome of which displays a broadened ${ }^{1}$ MLCT band comparable to the one observed in the D1-C-A1 solution state UV-Vis 
spectrum with a slight $\lambda_{\max }$ red-shift of ca. $10 \mathrm{~nm}$ (Figure 2C). This shift is attributed to the increased conjugation in the ligands through rigidification induced planarization of the peripheral planar aromatic groups when attached to $\mathrm{ZnO}$. Diffuse reflectance Fourier transform infrared spectroscopy (DRIFTS) analysis gave further evidence for presumptive attachment of the D1-CA1 triad onto the surface of $\mathrm{ZnO}$ nanoparticles prepared in a method analogous to the functionalized films (Figure 2D). The broad mode centered at $3381 \mathrm{~cm}^{-1}$ is attributed to the stretching vibration of $\mathrm{N}-\mathrm{H}$ from the bridge formed between the NMI moiety and the semiconductor surface bound (3-aminopropyl)triethoxysilane (APTES) ${ }^{29}$ The modes centered between $2800-3000 \mathrm{~cm}^{-1}$ are typical of $\mathrm{sp}^{2}$ stretching vibrations arising from aromatic $\mathrm{C}-\mathrm{H}$ bonds of APTES and aromatic rings of D1-C-A1. The Zn-O-Si and Si-O-Si bond stretching modes appear at $1119 \mathrm{~cm}^{-1}$ and $885 \mathrm{~cm}^{-1}$ respectively. ${ }^{30,31}$

Photocurrent measurements on the as-fabricated photoelectrodes were carried out using a three electrode photoelectrochemical cell (PEC) composed of ZnO NWs|A1-C-D1 as the working electrode, $\mathrm{Ag} / \mathrm{AgCl}(3 \mathrm{M} \mathrm{KCl})$ as the reference electrode and a Pt wire as the counter electrode. The PEC was illuminated with white light (four passively cooled individual Cree XM-L2 LEDs arranged in a box around the sample) in aqueous $1 \mathrm{M} \mathrm{Na}_{2} \mathrm{SO}_{4}$ without an applied bias vs. $\mathrm{Ag} / \mathrm{AgCl}$. Upon illumination, the ZnO NWs|A1-C-D1 films show a high initial photocurrent (ca. $5 \mu \mathrm{A} \mathrm{cm}^{-2}$, Figure 4A), which is due to electron injection from the surface bound D1-C-A1 system into the conduction band of the $\mathrm{ZnO}$ nanostructures. Photocurrent of this amplitude is somewhat lower than related Ru-based systems (Table S1), and we attribute this to a lower degree of surface coverage by the triad, perhaps owing to incomplete reactions during the grafting step. As observed through the presence of local capacitance effects, we conclude that the regeneration of the ground state D1-C-A1 system is slower than electron injection into the $\mathrm{ZnO}$ conduction band (Figure $\mathrm{S} 3$ ). 
On addition of triethylamine (TEA) as a sacrificial electron donor, and to observe the maximum photocurrent possible for this system, an enhanced photocurrent (ca. $12 \mu \mathrm{A} \mathrm{cm}^{-2}$ ) and nearly no capacitance effects were observed (Figure 4A, Figure S3). The higher amplitude photocurrent with addition of a sacrificial donor reflects a higher yield of electron injection into $\mathrm{ZnO}$ resulting from faster D1-C-A1 regeneration kinetics. The lack of local capacitance also indicates faster regeneration of the ground state D1-C-A1 assembly. We observed minimal changes in the photocurrent density for up to 10 chopped light cycles confirming the inherent stability of our photoelectrode. 

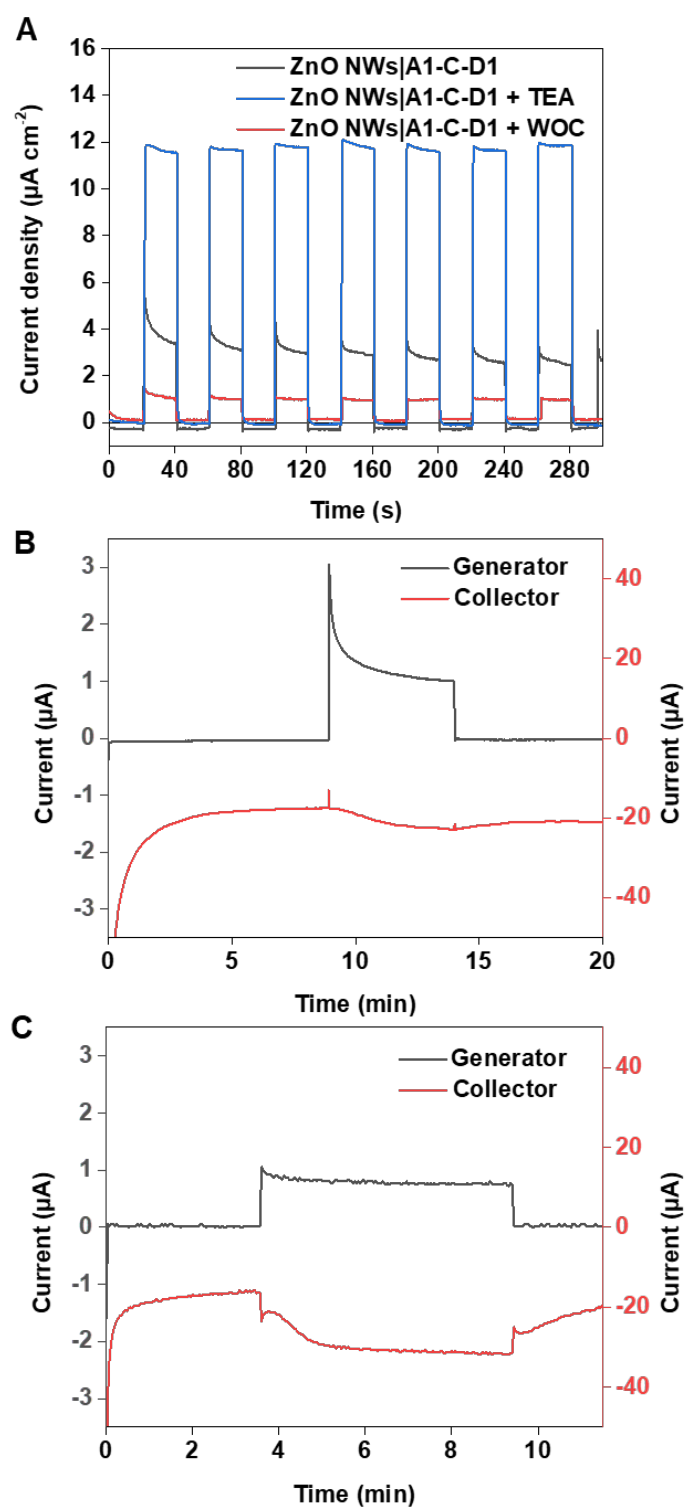

Figure 4. A) Chopped-light chronoamperometry experiments of ZnO NWs|A1-C-D1 (black), with triethylamine as a sacrificial electron donor (blue) and with WOC (red) in $1 \mathrm{M} \mathrm{Na} 2 \mathrm{SO}_{4} / \mathrm{NaOH}$ solution adjusted to $\mathrm{pH}$ 12; reference electrode: $\mathrm{Ag} / \mathrm{AgCl}$, counter electrode: Pt Wire. B) Collectorgenerator dual working electrode experiments on an ZnO NWs $\mid$ A1-C-D1 film without WOC and C) collector-generator dual working electrode experiments on an ZnO NWs $\mid$ A1-C-D1 film with WOC. The generator electrodes were held at zero applied bias and illuminated using white light. 
The collector-electrode for each experiment was held at an applied bias of $-0.40 \mathrm{~V}$ vs $\mathrm{Ag}$ wire. (Conditions: $1.0 \mathrm{M} \mathrm{Na}_{2} \mathrm{SO}_{4}$ at $\mathrm{pH}$ 12, $\mathrm{RE} ; \mathrm{Ag} / \mathrm{AgCl} ; \mathrm{CE}$; Pt wire).

To verify the importance of employing a D-C-A triad (versus simply a dyad or bare chromophore), particularly one bearing carbazole, similar studies were carried out using ZnO NWs $\mid$ A1-C as the working electrode. In this arrangement, upon light illumination, lower photocurrent $\left.(<1 \mu \mathrm{A} \mathrm{cm})^{-2}\right)$ with nearly no capacitance effects was observed as compared with ZnO NWs|A1-C-D1 under identical experimental conditions (Figure S4). ${ }^{32}$ We hypothesize that this is due to a higher rate of charge recombination arising from a decreased degree of spatial separation of the electron-hole pair.

To probe the efficacy of our photoelectrode architecture as a photocatalytic surface for water oxidation, we paired it with the previously reported water-soluble electrocatalyst $[($ bpy $) \mathrm{Cu}(\mu-$ $\mathrm{OH}]_{2}\left[\mathrm{SO}_{4}\right]$ (WOC) that has been shown to be active across a $\mathrm{pH}$ range of $11.8-13.0$ at an oxidation potential of $1.45 \mathrm{~V} .{ }^{16,33}$ While this oxidation potential appears to be outside of the range of the excited state redox potentials of the D-C-A, we anticipate it is accessible to the oxidized carbazole moiety (Scheme S4). A three electrode PEC system containing $0.1 \mathrm{mM}$ of WOC catalyst was illuminated with white light in aqueous $0.1 \mathrm{M} \mathrm{NaOH} / \mathrm{Na}_{2} \mathrm{SO}_{4}(\mathrm{pH}$ 12) without applying any bias vs. $\mathrm{Ag} / \mathrm{AgCl}$. In the presence of the WOC and with the ZnO NWs|A1-C-D1 as the working electrode, we observed a photocurrent decrease (ca. $1 \mu \mathrm{A} \mathrm{cm}{ }^{-2}$ ) as compared to the photoanode in solution free of catalyst with a marked decrease in capacitive effects (Figure 4A), correlating to results observed for analogous photoanode systems and suggesting oxidation of the WOC. . $^{3-36}$ Furthermore, charge accumulation and the ability to drive water oxidation was investigated via $\mathrm{O}_{2}$ detection using a four electrode collector-generator electrochemical experiment, where a 
functionalized ZnO NWs|A1-C-D1 film (the generator) was separated by $1 \mathrm{~mm}$ from a bare FTO (the collector) held at a potential capable of reducing $\mathrm{O}_{2} \cdot{ }^{9,36-41}$ This technique has been shown to be a convenient and simple method for $\mathrm{O}_{2}$ analysis in electrochemical and photoelectrochemical water oxidation, the validity of which has been confirmed previously using a Clark-type oxygen sensor. ${ }^{9,38,39,41-46}$ On illumination, in the absence of WOC in solution, a small increase in the current response of collector electrode was observed signifying that even without a water oxidation catalyst the photoanode is generating $\mathrm{O}_{2}$ that is then being reduced at the collector electrode (Figure 4B). A Faradaic efficiency of $24 \%$ for the cell was calculated using a chronocoloumbic method (Eqn S1). When the same experiment was conducted in the presence of the WOC, the current at the collector electrode rose to a maximum, plateaued and gradually decayed back to background current on extinguishing the illumination indicating diffusion of residual oxygen (Figure 4C). The Faradaic efficiency in the presence of WOC was determined to be $76 \%$. This efficiency is somewhat lower than the $90 \%$ electrocatalytic Faradaic efficiency reported previously for this catalyst, but higher than that observed for the system in the absence of catalyst. ${ }^{16}$ This efficiency is also somewhat surprising given the perceived mismatch between the oxidation potential of the WOC catalyst and the excited state redox potential of the D-C-A triad. The significant difference between the Faradaic efficiencies of oxygen generation in the absence versus presence of the molecular WOC, concomitant with the evolution of current at the collector electrode confirms successful photodriven oxidation of WOC at the ZnO NWs|A1-C-D1 photoanode and likely the generation of $\mathrm{O}_{2}$. A longer illumination experiment was conducted to check the stability of our system where the current at the collector electrode was found to continue to increase even after one hour of irradiation time indicating the sustained activity of our photoanode (Figure S5) even at the high $\mathrm{pH}$ required for this particular water oxidation catalyst. 
We attribute this prolonged stability to the passivation of the amphoteric $\mathrm{ZnO}$ NWs by a monolayer of APTES installed during the functionalization process. ${ }^{47}$ No $\mathrm{O}_{2}$ evolution at the collector electrode was observed when ZnO NWs|A1-C was employed as the working generator electrode (Figure S6), validating the importance of the excited state contribution from the carbazole moiety in D1. While outside the scope of the present work, we are continuing to probe for the presence of a 2c,3e O-O putative intermediate oxidized at the $\mathrm{Cu}-\mathrm{O}$ bond using various in situ spectroscopic techniques to improve the catalytic qualities of our system, and to evaluate the feasibility of coanchoring this particular WOC to the $\mathrm{ZnO}$ NW surface. ${ }^{33}$

In conclusion, we have designed and studied a new donor-chromophore-acceptor $\mathrm{Cu}(\mathrm{I})$-based triad D1-C-A1 for use as a photosensitizing agent in conjunction with a $\mathrm{Cu}(\mathrm{II})$-based catalyst in a water oxidation scheme. To our knowledge, the present $\mathrm{Cu}(\mathrm{II})$ WOC has never been photodriven, and of the growing number of DS-PEC systems known, many employ well-studied, but precious metal Ru-based catalysts/chromophores, organic chromophores, or a high applied bias (Table S1). While the photocurrent densities reached by the photoelectrodes reported here are lower than many previously reported photoanodes, we note that the observed Faradaic efficiency for this system (without the intervention of any techniques to stabilize the chromophore on the semiconductor surface) compares favourably with literature examples. Experiments are underway to attach the $\mathrm{Cu}(\mathrm{II})$-based catalyst on the surface along with D1-C-A1 in order to improve the efficiency, rate of catalyst oxidation and better hole transfer dynamics between the adsorbed triad and the catalyst in addition to time-resolved spectroscopic experiments to probe the kinetics or charge transfer between all of the system components.

\section{ASSOCIATED CONTENT}




\section{Supporting Information}

Procedures for the syntheses of ligands, complexes, $\mathrm{ZnO}$ nanowire films, and device fabrication, characterization, and supporting photoelectrochemical studies, DFT studies and NMR analysis.

\section{AUTHOR INFORMATION}

\section{Corresponding Author}

Email: marek.majewski@concordia.ca

\section{Author Contributions}

Z.S. carried out all experimental work. Computational analysis was carried out by P.R.D. The manuscript was written through contributions of all authors. All authors have given approval to the final version of the manuscript.

\section{Notes}

The authors declare no competing financial interest.

\section{ACKNOWLEDGMENT}

The authors thank the Natural Sciences and Engineering Research Council of Canada (NSERC), the Fonds de Recherche du Québec - Nature et technologies (FRQNT) and the Quebec Centre for Advanced Materials (QCAM) for financial support. Z.S. thanks the Faculty of Arts and Science, Concordia University for financial support. Mass spectrometry was carried out at the Centre for Biological Applications of Mass Spectrometry (CBAMS) and ground state spectroscopic measurements were carried out at the Integrated Platform for Biomolecular Function, Interactions and Structure (BIOFINS) at Concordia University. Diffuse reflectance UV-Vis and profilometry experiments were carried out with the assistance of Dr. Daniel Chartrand at the Laboratoire 
d'Analyse des Molécules et des Matériaux Photoactifs (LAMP). Computational investigations were enabled in part by support provided by Calcul Québec and Compute Canada. SEM experiments were performed at Centre de caractérisation microscopique des matériaux $(\mathrm{CM})^{2}$ with the help of Joseph Ricardo-Noordberg.

\section{REFERENCES}

(1) Alstrum-Acevedo, J. H.; Brennaman, M. K.; Meyer, T. J. Chemical Approaches to Artificial Photosynthesis. 2. Inorg. Chem. 2005, 44 (20), 6802.

(2) Hammarström, L. Accumulative Charge Separation for Solar Fuels Production: Coupling Light-Induced Single Electron Transfer to Multielectron Catalysis. Acc. Chem. Res. 2015, 48 (3), 840.

(3) Gao, Y.; Ding, X.; Liu, J.; Wang, L.; Lu, Z.; Li, L.; Sun, L. Visible Light Driven Water Splitting in a Molecular Device with Unprecedentedly High Photocurrent Density. J. Am. Chem. Soc. 2013, 135 (11), 4219.

(4) Song, W.; Glasson, C. R. K.; Luo, H.; Hanson, K.; Brennaman, M. K.; Concepcion, J. J.; Meyer, T. J. Photoinduced Stepwise Oxidative Activation of a Chromophore-Catalyst Assembly on TiO2. J. Phys. Chem. Lett. 2011, 2 (14), 1808.

(5) Song, W.; Ito, A.; Binstead, R. A.; Hanson, K.; Luo, H.; Brennaman, M. K.; Concepcion, J. J.; Meyer, T. J. Accumulation of Multiple Oxidative Equivalents at a Single Site by Cross-Surface Electron Transfer on TiO2. J. Am. Chem. Soc. 2013, 135 (31), 11587.

(6) Sandroni, M.; Maufroy, A.; Rebarz, M.; Pellegrin, Y.; Blart, E.; Ruckebusch, C.; Poizat, O.; Sliwa, M.; Odobel, F. Design of Efficient Photoinduced Charge Separation in DonorCopper(I)-Acceptor Triad. J. Phys. Chem. C 2014, 118 (49), 28388.

(7) Wang, M.; Na, Y.; Gorlov, M.; Sun, L. Light-driven hydrogen production catalysed by transition metal complexes in homogeneous systems. Dalton Trans. 2009, (33), 6458.

(8) Wenger, O. Long-range electron transfer in artificial systems with d6 and d8 metal photosensitizers. Coord. Chem. Rev. 2009, 253, 1439.

(9) Wang, D.; Sampaio, R. N.; Troian-Gautier, L.; Marquard, S. L.; Farnum, B. H.; Sherman, B. D.; Sheridan, M. V.; Dares, C. J.; Meyer, G. J.; Meyer, T. J. Molecular Photoelectrode for Water Oxidation Inspired by Photosystem II. J. Am. Chem. Soc. 2019, 141 (19), 7926.

(10) Gosztola, D.; Niemczyk, M. P.; Svec, W.; Lukas, A. S.; Wasielewski, M. R. Excited Doublet States of Electrochemically Generated Aromatic Imide and Diimide Radical Anions. J. Phys. Chem. A 2000, 104 (28), 6545.

(11) Fürer, S.; Bozic-Weber, B.; Neuburger, M.; Constable, E.; Housecroft, C. Heteroleptic copper(I) sensitizers with one versus two hole-transporting units in functionalized 2,9dimethyl-1,10-phenanthroline ancillary ligands. RSC Adv. 2015, 5, 69430.

(12) Dragonetti, C.; Magni, M.; Colombo, A.; Fagnani, F.; Roberto, D.; Melchiorre, F.; Biagini, P.; Fantacci, S. Towards efficient sustainable full-copper dye-sensitized solar cells. Dalton Trans. 2019, 48 (26), 9703. 
(13) Franco, F.; Cometto, C.; Garino, C.; Minero, C.; Sordello, F.; Nervi, C.; Gobetto, R. Photoand Electrocatalytic Reduction of $\mathrm{CO} 2$ by $\left[\operatorname{Re}(\mathrm{CO}) 3\left\{\alpha, \alpha^{\prime}\right.\right.$-Diimine-(4-piperidinyl-1,8naphthalimide)\}Cl] Complexes. Eur. J. Inorg. Chem. 2014, 2015, 296.

(14) Sandroni, M.; Kayanuma, M.; Planchat, A.; Szuwarski, N.; Blart, E.; Pellegrin, Y.; Daniel, C.; Boujtita, M.; Odobel, F. First application of the HETPHEN concept to new heteroleptic bis(diimine) copper(i) complexes as sensitizers in dye sensitized solar cells. Dalton Trans. 2013, 42 (30), 10818.

(15) Schmittel, M.; Ganz, A. Stable mixed phenanthroline copper(i) complexes. Key building blocks for supramolecular coordination chemistry. Chem. Commun. 1997, (11), 999.

(16) Barnett, S.; Goldberg, K.; Mayer, J. A soluble copper-bipyridine water-oxidation electrocatalyst. Nat. Chem. 2012, 4, 498.

(17) Garribba, E.; Micera, G.; Sanna, D.; Strinna-Erre, L. The Cu(II)-2,2'-bipyridine system revisited. Inorg. Chim. Acta 2000, 299 (2), 253.

(18) Rupp, M.; Auvray, T.; Rousset, E.; Mercier, G. M.; Marvaud, V.; Kurth, D. G.; Hanan, G. S. Photocatalytic Hydrogen Evolution Driven by a Heteroleptic Ruthenium(II) Bis(terpyridine) Complex. Inorg. Chem. 2019, 58 (14), 9127.

(19) Barbieri, A.; Accorsi, G.; Armaroli, N. Luminescent complexes beyond the platinum group: the d10 avenue. Chem. Commun. 2008, (19), 2185.

(20) Matheu, R.; Garrido-Barros, P.; Gil-Sepulcre, M.; Ertem, M. Z.; Sala, X.; GimbertSuriñach, C.; Llobet, A. The development of molecular water oxidation catalysts. Nat. Rev. Chem. 2019, 3 (5), 331.

(21) Hankache, J.; Niemi, M.; Lemmetyinen, H.; Wenger, O. S. Photoinduced Electron Transfer in Linear Triarylamine-Photosensitizer-Anthraquinone Triads with Ruthenium(II), Osmium(II), and Iridium(III). Inorg. Chem. 2012, 51 (11), 6333.

(22) Barea, E. M.; Zafer, C.; Gultekin, B.; Aydin, B.; Koyuncu, S.; Icli, S.; Santiago, F. F.; Bisquert, J. Quantification of the Effects of Recombination and Injection in the Performance of Dye-Sensitized Solar Cells Based on N-Substituted Carbazole Dyes. $J$. Phys. Chem. C 2010, 114 (46), 19840.

(23) Chaurasia, S.; Liang, C.-J.; Yen, Y.-S.; Lin, J. T. Sensitizers with rigidified-aromatics as the conjugated spacers for dye-sensitized solar cells. J. Mater. Chem. C 2015, 3 (38), 9765.

(24) Estrella, L. L.; Balanay, M. P.; Kim, D. H. The Effect of Donor Group Rigidification on the Electronic and Optical Properties of Arylamine-Based Metal-Free Dyes for DyeSensitized Solar Cells: A Computational Study. J. Phys. Chem. A 2016, 120 (29), 5917.

(25) Guo, C. X.; Dong, Y.; Yang, H. B.; Li, C. M. Graphene Quantum Dots as a Green Sensitizer to Functionalize $\mathrm{ZnO}$ Nanowire Arrays on F-Doped $\mathrm{SnO} 2$ Glass for Enhanced Photoelectrochemical Water Splitting. Adv. Energy Mater. 2013, 3 (8), 997.

(26) Zeng, X.; Zhou, Y.; Ma, W.; Wang, S.; Xie, K.; Wu, J.; Wei, K. Selective Zn (II) chemosensor based on di(2-picolyl)amine functionalized inorganic/organic hybrid magnetic network. Chem. Eng. J. 2014, 244, 75.

(27) Niu, C.-G.; Qin, P.-Z.; Zeng, G.-M.; Gui, X.-Q.; Guan, A.-L. Fluorescence sensor for water in organic solvents prepared from covalent immobilization of 4-morpholinyl-1, 8naphthalimide. Anal. Bioanal. Chem. 2007, 387 (3), 1067.

(28) Zanatta, L. D.; Barbosa, I. A.; Zanardi, F. B.; de Sousa Filho, P. C.; Bolzon, L. B.; Ramos, A. P.; Serra, O. A.; Iamamoto, Y. Hydrocarbon oxidation by iron-porphyrin immobilized on SBA-15 as biomimetic catalyst: role of silica surface. $R S C A d v$. 2016, 6 (106), 104886. 
(29) Teo, L.-S.; Chen, C.-Y.; Kuo, J.-F. Fourier Transform Infrared Spectroscopy Study on Effects of Temperature on Hydrogen Bonding in Amine-Containing Polyurethanes and Poly(urethane-urea)s. Macromolecules 1997, 30 (6), 1793.

(30) Guo, Y.; Wang, H.; He, C.; Qiu, L.; Cao, X. Uniform Carbon-Coated ZnO Nanorods: Microwave-Assisted Preparation, Cytotoxicity, and Photocatalytic Activity. Langmuir 2009, 25 (8), 4678.

(31) Lee, J.; Choi, S.; Bae, S. J.; Yoon, S. M.; Choi, J. S.; Yoon, M. Visible light-sensitive APTES-bound $\mathrm{ZnO}$ nanowire toward a potent nanoinjector sensing biomolecules in a living cell. Nanoscale 2013, 5 (21), 10275.

(32) Ashbrook, L. N.; Elliott, C. M. Dye-Sensitized Solar Cell Studies of a Donor-Appended Bis(2,9-dimethyl-1,10-phenanthroline) Cu(I) Dye Paired with a Cobalt-Based Mediator. $J$. Phys. Chem. C 2013, 117 (8), 3853.

(33) Funes-Ardoiz, I.; Garrido-Barros, P.; Llobet, A.; Maseras, F. Single Electron Transfer Steps in Water Oxidation Catalysis. Redefining the Mechanistic Scenario. ACS Catal. 2017, 7 (3), 1712.

(34) Lapides, A. M.; Sherman, B. D.; Brennaman, M. K.; Dares, C. J.; Skinner, K. R.; Templeton, J. L.; Meyer, T. J. Synthesis, characterization, and water oxidation by a molecular chromophore-catalyst assembly prepared by atomic layer deposition. The "mummy" strategy. Chem. Sci. 2015, 6 (11), 6398.

(35) Kamire, R. J.; Materna, K. L.; Hoffeditz, W. L.; Phelan, B. T.; Thomsen, J. M.; Farha, O. K.; Hupp, J. T.; Brudvig, G. W.; Wasielewski, M. R. Photodriven Oxidation of SurfaceBound Iridium-Based Molecular Water-Oxidation Catalysts on Perylene-3,4dicarboximide-Sensitized TiO2 Electrodes Protected by an A12O3 Layer. J. Phys. Chem. C 2017, 121 (7), 3752.

(36) Eom, Y. K.; Nhon, L.; Leem, G.; Sherman, B. D.; Wang, D.; Troian-Gautier, L.; Kim, S.; Kim, J.; Meyer, T. J.; Reynolds, J. R.et al. Visible-Light-Driven Photocatalytic Water Oxidation by a $\pi$-Conjugated Donor-Acceptor-Donor Chromophore/Catalyst Assembly. ACS Energy Lett. 2018, 3 (9), 2114.

(37) Sherman, B. D.; Sheridan, M. V.; Dares, C. J.; Meyer, T. J. Two Electrode CollectorGenerator Method for the Detection of Electrochemically or Photoelectrochemically Produced O2. Anal. Chem. 2016, 88 (14), 7076.

(38) Sherman, B. D.; Xie, Y.; Sheridan, M. V.; Wang, D.; Shaffer, D. W.; Meyer, T. J.; Concepcion, J. J. Light-Driven Water Splitting by a Covalently Linked Ruthenium-Based Chromophore-Catalyst Assembly. ACS Energy Lett. 2017, 2 (1), 124.

(39) Wang, D.; Marquard, S. L.; Troian-Gautier, L.; Sheridan, M. V.; Sherman, B. D.; Wang, Y.; Eberhart, M. S.; Farnum, B. H.; Dares, C. J.; Meyer, T. J. Interfacial Deposition of $\mathrm{Ru}(\mathrm{II})$ Bipyridine-Dicarboxylate Complexes by Ligand Substitution for Applications in Water Oxidation Catalysis. J. Am. Chem. Soc. 2018, 140 (2), 719.

(40) Wang, D.; Sheridan, M. V.; Shan, B.; Farnum, B. H.; Marquard, S. L.; Sherman, B. D.; Eberhart, M. S.; Nayak, A.; Dares, C. J.; Das, A. K.et al. Layer-by-Layer Molecular Assemblies for Dye-Sensitized Photoelectrosynthesis Cells Prepared by Atomic Layer Deposition. J. Am. Chem. Soc. 2017, 139 (41), 14518.

(41) Wang, D.; Wang, L.; Brady, M. D.; Dares, C. J.; Meyer, G. J.; Meyer, T. J.; Concepcion, J. J. Self-Assembled Chromophore-Catalyst Bilayer for Water Oxidation in a DyeSensitized Photoelectrosynthesis Cell. J. Phys. Chem. C 2019, 123 (50), 30039. 
(42) Alibabaei, L.; Dillon, R. J.; Reilly, C. E.; Brennaman, M. K.; Wee, K.-R.; Marquard, S. L.; Papanikolas, J. M.; Meyer, T. J. Chromophore-Catalyst Assembly for Water Oxidation Prepared by Atomic Layer Deposition. ACS Appl. Mater. Interfaces 2017, 9 (44), 39018.

(43) Eberhart, M. S.; Wang, D.; Sampaio, R. N.; Marquard, S. L.; Shan, B.; Brennaman, M. K.; Meyer, G. J.; Dares, C.; Meyer, T. J. Water Photo-oxidation Initiated by Surface-Bound Organic Chromophores. J. Am. Chem. Soc. 2017, 139 (45), 16248.

(44) Wang, D.; Eberhart, M. S.; Sheridan, M. V.; Hu, K.; Sherman, B. D.; Nayak, A.; Wang, Y.; Marquard, S. L.; Dares, C. J.; Meyer, T. J. Stabilized photoanodes for water oxidation by integration of organic dyes, water oxidation catalysts, and electron-transfer mediators. Proc. Natl. Acad. Sci. U.S.A. 2018, 115 (34), 8523.

(45) Wu, L.; Eberhart, M.; Nayak, A.; Brennaman, M. K.; Shan, B.; Meyer, T. J. A Molecular Silane-Derivatized $\mathrm{Ru}(\mathrm{II})$ Catalyst for Photoelectrochemical Water Oxidation. J. Am. Chem. Soc. 2018, 140 (44), 15062.

(46) Liu, Q.; Wang, D.; Shan, B.; Sherman, B. D.; Marquard, S. L.; Eberhart, M. S.; Liu, M.; Li, C.; Meyer, T. J. Light-driven water oxidation by a dye-sensitized photoanode with a chromophore/catalyst assembly on a mesoporous double-shell electrode. J. Chem. Phys. 2019, 150 (4), 041727.

(47) Fu, P.; Guo, X.; Wang, S.; Ye, Y.; Li, C. Aminosilane as a Molecular Linker between the Electron-Transport Layer and Active Layer for Efficient Inverted Polymer Solar Cells. ACS Appl. Mater. Interfaces 2017, 9 (15), 13390. 